\title{
Estimation of Loss of Life due to Hot Spot Development in Power Transformer using MATLAB
}

\author{
Jayashri Vajpai ${ }^{1}$ and Vinit Mehta ${ }^{2}$
}

\begin{abstract}
The opportunity for the research in thermal modeling of power transformer is to estimate their loss of life due to overloading by employing the winding hot spot temperature (HST) and by carrying out aging studies based on heat transfer theory. This is facilitated by developing computational thermal models and their simulation using appropriate software tools. These models are employed to evaluate the actual functional age of transformers by estimating enhanced equivalent life at the reference temperature that will be spent over the specified time period for the given temperature cycle due to acceleration of aging. This paper presents a MATLAB/ Simulink based model for this purpose. The life determines the aging acceleration factor, which has been used for estimation of the loss of life of the transformer. Further, the effect of cooling for reducing the loss of life has also been studied. The proposed model has been validated using real time data gathered from a power transformer in field operation.
\end{abstract}

Keywords - Acceleration of aging, hot spot temperature, loss of life, thermal modeling.

\section{INTRODUCTION}

The operational efficiency and the economic viability of power systems are governed largely by the functioning and the cost of its constituent power transformers. The reliability of power systems is adversely affected by the failure and maloperation of power transformers. These occur due to the failure of insulation caused by high stress under abnormal or critical operating conditions or in cases when heat generated in a power transformer is not dissipated efficiently by the surrounding medium. Generally, hot spots are developed in the power transformers when the heat dissipation is not uniform or effective, leading to thermal stress.

This paper presents a technique for estimating the loss of life of transformer by modeling the thermal stresses that are responsible for the deterioration of their quality and performance and employing them to calculate accelerated aging. The most important factor among these is the hot spot temperature (HST), which is a major reason for the loss of life of transformer. The HST of a transformer primarily depends on the ambient temperature, the rise in the top oil temperature (TOT) over the ambient temperature and the rise in the winding HST over the top oil temperature. HST values for different load conditions can be estimated by considering appropriate

Manuscript Dec. 10, 2015. This work was supported in part by the Engineers at 400kV GSS, Surpura, Jodhpur (Rajasthan, India).

Jaishree Vajpai, Ph.D., is serving as Associate Professor in MBM Engineering College, JNV University, Jodhpur (Rajasthan, India).

Vinit Mehta is serving as Sr. Assistant Professor in Jodhpur Institute of Engineering and Technology, Jodhpur (Rajasthan, India). computational model on the basis of the thermal characteristics of the transformer and the cooling system.

This paper proposes a computational model that has been simulated on MATLAB/Simulink and that has provision for evaluation of the HST for every hour in a given load cycle. This is employed to estimate the aging acceleration factor. The percentage loss of life is predicted on the basis of these values. Further, by providing Oil Natural Air Forced (ONAF) cooling arrangement during peak load period, the saving in percentage loss of life is determined. The proposed model has been used to predict the loss of life of a 315MVA power transformer in operation at 400kV GSS, Surpura, Jodhpur (Rajasthan, India). After Introduction, the paper includes five more sections, that present the state of art, proposed methodology, algorithm, MATLAB/ Simulink model, results and discussion.

\section{StATE OF ART}

In order to overcome the abnormal operating conditions and to increase the transformer loading capacity, different calculation procedures for estimating the winding hot spot temperature with reference to load changes have been proposed by many authors.

The base of their work is primarily IEEE or IEC guidelines. IEEE Guide for Loading Mineral-Oil-Immersed Transformers [1] is applicable to loading mineral-oil-immersed distribution and power transformers, with different types of construction, along with special considerations for the degree of conservatism involved in the loading. This has paved the way for understanding and developing models for the simulation of thermal characteristics of power transformers as attempted in this paper. Hashmi et. al. [2] have performed the steady-state calculations using IEC guidelines to determine the hot spot temperatures of distribution and power transformers in the worst environment due to long summer periods. Amoda et. al. [3] have presented an investigation into the adequacy of the IEEE HST model, when the model parameters are to be determined from measured field data.

Shiyou et. al. [4] have analyzed the mechanism of thermogenesis and thermolysis of transformer along with the position of the hotspot temperature. Further, the calculation of the loss of insulation life of dry-type transformer has been carried out on the basis of HST. Silva and Bastos [5] have addressed the influence of simplifications to be made on the geometries of power transformers for the performance of thermodynamic simulations to diminish the computational time and to obtain the magnetic fields, temperatures and heat flow in the interior of the transformer. Humayun et. al. [6] have proposed demand response and dynamic thermal rating based optimization model for efficient capacity utilization and life 
management of transformers during contingencies. Kweon et. al. [7] have estimated the hot spot temperature in the power transformer by the optical fiber sensors and validated it by the conventional heat run test. Gouda et. al. [8] have introduced the HST and TOT based thermal model under linear and non-linear loads. Vanegas and Mahajan [9] have determined the thermal characteristics, load profiles and acceleration factor equation of an oil-immersed current transformer and compared the estimated and expected values of the aging acceleration factor. Dejan Suja et. al. [10] have presented an accurate temperature calculation method based on the thermal-electrical analogy that considers nonlinear thermal resistances at different locations within a power transformer. Yong Liang [11] has developed a graphical tool for predicting TOT using a semi-physical model to assess the effect of solar radiation and wind velocity on the prediction of TOT.

Muhamad et. al. [12] have investigated the effect of HST on the overall transformer temperature distribution and its effect on the heat dissipation to the surface of transformer tank, for condition monitoring purposes. Further, simulation of mineral oil-filled distribution transformer (ONAN type) has been done by using Finite Element Method Magnetism software. Longnv et. al. [13] have presented an accurate computational alternative for hot-spot temperature-rise estimations in a single-phase auto-transformer to compute the stray losses using finite-element method (FEM), along with the average surface convection heat transfer coefficients of the structural parts of the transformer. Radakovic et. al. [14] have developed a detailed thermal-hydraulic network model for determining the value of the hot-spot factor and the HST using FEM. Srinivasan [15] has proposed a semi-physical model comprising of variable environmental conditions for the estimation of HST in transformer and along with a MATLAB/Simulink-based valid model. Takami et. al. [16] have done an online monitoring of the transformer using FEMLAB and MATLAB software to estimate the HST of an oil-immersed power transformers.

In general, many simplifying assumptions have been made in the various proposed methods for calculating the HST of power transformers, as reported in the standards documentation and published literature. The aim of this paper is to develop a comprehensive computational methodology for thermal model of power transformer, for estimating accelerated aging factor and loss of life, along with ease of application offered by the MATLAB software.

\section{Proposed Methodology}

This section presents the salient features of the proposed thermal modeling of a three-phase power transformer by using MATLAB software and uses it to estimate the loss of life of the power transformer. The theoretical aspects of the estimation of loss of life are first described, followed by the algorithm.

\section{A. Thermal Modeling of Top Oil Temperature Rise}

The rise of top oil temperature over ambient temperature is an indication of continuous loading of transformer. An increase in the load increases the losses thus increasing the overall temperature. The rate of change of temperature depends upon the overall thermal time constant of the transformer, which in turn depends upon the heat capacity of the transformer, i.e. the mass of the core, coils, and oil, and the rate of heat exchange from the transformer. The change of top oil temperature is modeled as a first-order differential equation as follows [10].

$\mathrm{T}_{\mathrm{TO}} \frac{\mathrm{d} \Delta \theta_{\mathrm{TO}}(\mathrm{t})}{\mathrm{dt}}=\Delta \theta_{\mathrm{TO}}(\mathrm{u})-\Delta \theta_{\mathrm{TO}}(\mathrm{t})$

where, $\mathrm{T}_{\mathrm{TO}}$ is the top oil time constant in minutes, $\Delta \theta_{\mathrm{TO}}(\mathrm{t})$ is the top oil temperature rise over ambient temperature in ${ }^{\circ} \mathrm{C}$, $\Delta \theta_{\mathrm{TO}}(\mathrm{u})$ is the final top oil temperature rise in ${ }^{\circ} \mathrm{C}$, and $\mathrm{t}$ is the time referenced to the time of the loading change.

Equation (1) is solved to obtain the following exponential response from the initial temperature state to the final temperature state [10],

$\Delta \theta_{\mathrm{TO}}(\mathrm{t})=\left[\Delta \theta_{\mathrm{TO}}(\mathrm{u})-\Delta \theta_{\mathrm{TO}}(\mathrm{i})\right]\left[1-\mathrm{e}^{-\mathrm{t} / \mathrm{T}_{\mathrm{TO}}}\right]+\Delta \theta_{\mathrm{TO}}(\mathrm{i})$

where, $\Delta \theta_{\mathrm{TO}}(\mathrm{i})$ is the initial top oil temperature rise in ${ }^{\circ} \mathrm{C}$.

The final rise in the top oil temperature depends upon the load factor and can be approximated by the following equation:

$\Delta \theta_{\mathrm{TO}}(\mathrm{u})=\Delta \theta_{\mathrm{TO}}(\mathrm{r})\left[\frac{\mathrm{K}^{2} \mathrm{R}+1}{\mathrm{R}+1}\right]^{\mathrm{n}}$

where, $\Delta \theta_{\mathrm{TO}}(\mathrm{r})$ is the full load top oil temperature rise over ambient temperature in ${ }^{\circ} \mathrm{C}, \mathrm{R}$ is the ratio of load loss at rated load to no-load loss, $\mathrm{K}$ is the ratio of the specified load to rated load, $\mathrm{n}$ is an empirically derived exponent that depends upon the cooling method. The IEEE loading guide [1] recommends the use of $n=0.8$ for natural convection and $n=0.9$ to1. 0 for forced cooling. The top oil time constant at the considered load is given by the following:

$\mathrm{T}_{\mathrm{TO}}=60 * \frac{\mathrm{C}_{\text {th-oil }}{ }^{* \Delta \theta_{\mathrm{TO}}(\mathrm{r})}}{\mathrm{q}_{\mathrm{tot}}}$

where, $\mathrm{q}_{\text {tot }}$ is the total supplied losses in $\mathrm{W}$, and $\mathrm{C}_{\text {th-oil }}$ is the equivalent thermal capacitance of the transformer oil in $\mathrm{W}-\mathrm{h} /{ }^{\circ} \mathrm{C}$.

The equivalent thermal capacitance of the transformer oil is given by the following equation:

$\mathrm{C}_{\text {th-oil }}=0.48 * \mathrm{M}_{\text {oil }}$

where, $\mathrm{M}_{\mathrm{Oil}}$ is the weight of the oil in $\mathrm{kg}$.

\section{B. Thermal Modeling of Hot Spot Temperature Rise}

The increase in the transformer current due to losses increases the oil and winding temperature. The change of hot spot temperature is modeled as a first-order differential equation shown in Equation(6) [10]:

$\mathrm{T}_{\mathrm{HS}} \frac{\mathrm{d} \Delta \theta_{\mathrm{HS}}(\mathrm{t})}{\mathrm{dt}}=\Delta \theta_{\mathrm{HS}}(\mathrm{u})-\Delta \theta_{\mathrm{HS}}(\mathrm{t})$

where, $\mathrm{T}_{\mathrm{HS}}$ is the hot spot time constant in minutes, $\Delta \theta_{\mathrm{HS}}(\mathrm{t})$ is the hot spot temperature rise over top oil temperature rise in ${ }^{\circ} \mathrm{C}$, $\Delta \theta_{\mathrm{HS}}(\mathrm{u})$ is the final hot spot temperature rise in ${ }^{\circ} \mathrm{C}$ and $\mathrm{t}$ is the time referenced to the time of the loading change.

This can be solved to obtain

$\Delta \theta_{\mathrm{HS}}(\mathrm{t})=\left[\Delta \theta_{\mathrm{HS}}(\mathrm{u})-\Delta \theta_{\mathrm{HS}}(\mathrm{i})\right]\left[1-\mathrm{e}^{-\mathrm{t} / \mathrm{T}_{\mathrm{HS}}}\right]+\Delta \theta_{\mathrm{HS}}(\mathrm{i})$ where, $\Delta \theta_{\mathrm{HS}}(\mathrm{i})$ is the initial hot spot temperature rise in ${ }^{\circ} \mathrm{C}$.

Based on the IEEE model, the final rise in the hot spot temperature considering the load factor can be obtained by the following equation:

$\Delta \theta_{\mathrm{HS}}(\mathrm{u})=\Delta \theta_{\mathrm{HS}}(\mathrm{r})[\mathrm{K}]^{2 \mathrm{~m}}$

where, $\Delta \theta_{\mathrm{HS}}(\mathrm{r})$ is the rated hot spot temperature rise over top oil temperature and $\mathrm{m}$ is an empirically derived exponent that depends on the cooling method.

The winding hot spot time constant can be calculated as follows:

$\mathrm{T}_{\mathrm{HS}}=2.75 * \frac{\Delta \theta_{\mathrm{HS}}(\mathrm{r})}{\left(1+\mathrm{P}_{\mathrm{e}}\right) * \mathrm{~S}^{2}}$ 
where, $\mathrm{T}_{\mathrm{HS}}$ is the winding hot spot time constant in minutes at the rated load, $\mathrm{P}_{\mathrm{e}}$ is the relative eddy current losses $(\mathrm{W}), \mathrm{S}$ is the current density in $\mathrm{A} / \mathrm{mm}^{2}$ at rated load.

Finally the hot spot temperature is calculated by adding the ambient temperature, the top oil temperature rise over ambient, and the hot spot temperature rise over top oil. This can be expressed by the following equation [1].

$\theta_{\mathrm{H}}=\theta_{\mathrm{A}}+\Delta \theta_{\mathrm{HS}}(\mathrm{t})+\Delta \theta_{\mathrm{TO}}(\mathrm{t})$

where, $\theta_{\mathrm{A}}$ is the ambient temperature in ${ }^{\circ} \mathrm{C}$ and $\theta_{\mathrm{H}}$ is the ultimate hot spot temperature in ${ }^{\circ} \mathrm{C}$.

\section{Estimation of Equivalent Aging Factor}

In oil-immersed transformers, paper or cellulose material along with oil forms the major insulation. Therefore, the insulation must maintain adequate dielectric strength against voltage surges and adequate mechanical strength against short-circuit forces.

As cellulose ages thermally in an operating transformer; three mechanisms contribute to its degradation, namely; hydrolysis, oxidation, and pyrolysis. The agents responsible for the respective mechanisms are water, oxygen, and heat. Each of these agents will have an effect on degradation rate so they must be individually controlled. Water and oxygen content of the insulation can be controlled by the transformer oil preservation system but control of heat is left to transformer operating personnel.

Transformer insulation life is defined as the total time period between the initial state for which the transformer insulation is considered new and the final state for which dielectric stress or short circuit stress could occur in normal service and cause an electrical failure.

Experimental evidence indicates that the relation of insulation deterioration to time and temperature follows an adaptation of the Arrhenius reaction rate theory that has the following form [1]:

Per unit life $=A * \exp \left[\frac{B}{\theta_{\mathrm{H}}+273}\right]$

where, $\mathrm{A}$ is a modified per unit constant and $\mathrm{B}$ is the aging rate. The temperature of $110^{\circ} \mathrm{C}$ is selected for one per unit life.

The Aging Acceleration Factor $\left(\mathrm{F}_{\mathrm{AA}}\right)$ per unit transformer insulation life is given by the following equation [1].

$\mathrm{F}_{\mathrm{AA}}=\exp \left[\frac{15000}{383}+\frac{15000}{\theta_{\mathrm{H}}+273}\right]$

The equivalent loss of life (in hours or days) at the reference temperature in a given time period for the given temperature cycle is given as follows.

$\mathrm{F}_{\mathrm{EQA}}=\frac{\sum_{\mathrm{n}=1}^{\mathrm{N}} \mathrm{F}_{\mathrm{AA}} * \Delta \mathrm{t}_{\mathrm{n}}}{\sum_{\mathrm{n}=1}^{\mathrm{N}} \Delta \mathrm{t}_{\mathrm{n}}}$

where, $\mathrm{F}_{\mathrm{EQA}}$ is the equivalent aging factor for the total time period, $\mathrm{n}$ is the index of the time interval, $\mathrm{N}$ is the total number of time intervals and $\mathrm{F}_{\mathrm{AAn}}$ is the aging acceleration factor for the temperature which exists during the time interval $\Delta \mathrm{t}_{\mathrm{n}}$.

\section{Estimation of Percentage Loss of Life}

The insulation per unit life curve is used to calculate percent loss of total life of a transformer. The normal insulation life at the reference temperature is defined in hours or years. The values of normal insulation life for a well-dried, oxygen-free system are given in Table I.
TABLE I: NORMAL INSULATION LIFE OF A WELL-DRIED, OXYGEN-FREE $65^{\circ} \mathrm{C}$ AVERAGE WINDING TEMPERATURE RISE INSULATION SYSTEM AT THE REFERENCE TEMPERATURE OF $110^{\circ} \mathrm{C}$ [1]

\begin{tabular}{lcc}
\hline \hline \multicolumn{1}{c}{ Basis } & \multicolumn{2}{c}{ Normal Insulation Life } \\
& Hours & Years \\
\hline $\begin{array}{l}\text { 50\% retained tensile strength of insulation } \\
\text { 25\% retained tensile strength of insulation }\end{array}$ & 65000 & 7.42 \\
$\begin{array}{l}\text { 200 retained degree of polymerization in } \\
\text { insulation }\end{array}$ & 135000 & 15.41 \\
$\begin{array}{l}\text { Interpretation of distribution Transformer } \\
\text { functional life test data }\end{array}$ & 180000 & 17.12 \\
\hline \hline
\end{tabular}

The percentage loss of life is given as follows:

Percentage Loss of Life $=\frac{\mathrm{F}_{\mathrm{EQA}} * \mathrm{t} * 100}{\text { Normal Insulation Life }}$

Further, by providing ONAF cooling arrangement during peak load period, the saving in percentage loss of life is determined. This can then be employed for the evaluation of residual life.

The algorithm for thermal modeling of the power transformer is now presented.

\section{AlgORITHM}

Step 1: Initialize the input variables of transformer on hourly basis. This includes load factor $\mathrm{K}$, total losses $\mathrm{q}(\mathrm{W})$, ambient temperature $\Delta \theta_{\mathrm{A}}\left({ }^{\circ} \mathrm{C}\right)$, OTI reading $\Delta \theta_{\mathrm{TO}}(\mathrm{i})\left({ }^{\circ} \mathrm{C}\right)$ and WTI reading $\Delta \theta_{\mathrm{HS}}(\mathrm{i})\left({ }^{\circ} \mathrm{C}\right)$ every hour in a given load cycle.

Step 2: The rated values of rated top oil rise over ambient temperature $\Delta \theta_{\mathrm{TO}}(\mathrm{r})\left({ }^{\circ} \mathrm{C}\right)$, rated hot spot rise over ambient temperature $\Delta \theta_{\mathrm{HS}}(\mathrm{r})\left({ }^{\circ} \mathrm{C}\right)$, exponent $\mathrm{n} \& \mathrm{~m}$, weight of oil $\mathrm{M}_{\mathrm{oil}}$ $(\mathrm{kg})$, current density $\mathrm{S}\left(\mathrm{A} / \mathrm{mm}^{2}\right)$, relative eddy current loss $\mathrm{P}_{\mathrm{e}}$ (W), ratio of load loss at rated load to no-load loss $\mathrm{R}$.

Step 3: The different values of final top oil temperature rise $\Delta \theta_{\mathrm{TO}}(\mathrm{u})\left({ }^{\circ} \mathrm{C}\right)$ are determined by placing the values of $\mathrm{K}, \mathrm{R}$ and $\mathrm{n}$ on hourly basis, using Equation (3).

Step 4: The different values of final hot spot temperature rise $\Delta \theta_{\mathrm{HS}}(\mathrm{u})\left({ }^{\circ} \mathrm{C}\right)$ are determined by placing the values of $\mathrm{K}$ and $\mathrm{m}$ on hourly basis, using Equation (8).

Step 5: The top oil time constant $\mathrm{T}_{\mathrm{TO}}$ (mins) is determined with the help of Equation (4).

Step 6: The hot spot time constant $\mathrm{T}_{\mathrm{HS}}$ (mins) is determined with the help of Equation (9).

Step 7: The top oil temperature rise $\Delta \theta_{\mathrm{TO}}\left({ }^{\circ} \mathrm{C}\right)$ is obtained from the application of Equation (2).

Step 8: The hot spot temperature rise $\Delta \theta_{\mathrm{HS}}\left({ }^{\circ} \mathrm{C}\right)$ is obtained from the application of Equation (7).

Step 9: The hot spot temperature $\theta_{\mathrm{H}}$ during a day on hourly basis is calculated using Equation (10).

Step 10: The aging acceleration factor is obtained using Equation (12).

Step 11: The equivalent aging of the power transformer is calculated by using Equation (13).

Step 12: The percentage loss of life is obtained from the application of Equation (14).

All the steps illustrated above, may be repeated for a load cycle that contains overload conditions during an hour for a day. The percentage loss of life thus calculated shows the amount of loss of life of transformer that can be used to estimate the reduced loss of life of the power transformer. 


\section{Matlab/SimulinK Model}

Fig. 1 shows a simplified block diagram of the MATLAB/ Simulink thermal dynamic model of a power transformer.

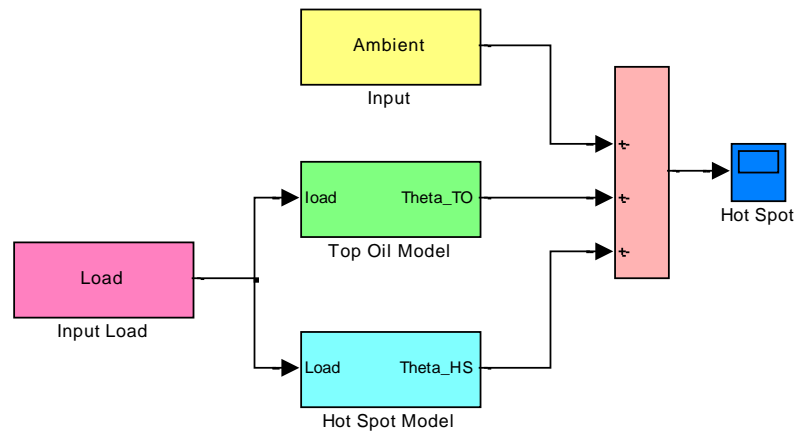

Fig. 1: Block diagram showing the thermal dynamic model of a power transformer

Equation (2) and Equation (7) are solved using MATLAB program for determination of the top oil temperature rise $\Delta \theta_{\mathrm{TO}}(\mathrm{t})$ and hot spot temperature rise $\Delta \theta_{\mathrm{HS}}(\mathrm{t})$ respectively. At each discrete time interval of 60 minutes, the top oil temperature rise and the hot spot winding temperature rise are calculated.

The hot spot temperature $\theta_{\mathrm{H}}$ is the sum of ambient temperature, top oil temperature rise and hot spot temperature rise. The measured hot spot temperature $\theta_{\mathrm{H}}$ results for a $315 \mathrm{MVA}, 400 / 33 \mathrm{kV}$ transformer during the given load cycle are then used to determine the residual life of the transformer.

\section{RESULTS \& DISCUSSION}

In order to validate the proposed model, data gathered under various load conditions from a real power transformer (315MVA) which are recorded in the month of January, have been used. In this study, work has been carried out in a power transformer situated at 400kV GSS, Surpura, Jodhpur substation. The specifications, cooling arrangements and temperature measuring equipments of the proposed power transformer are as shown in Table II, III and IV, respectively.

TABLE II: SPECIFICATION OF A 315MVA 400kV/33kV POWER TRANSFORMER

\begin{tabular}{ll}
\hline \hline & \\
\hline Rated voltage (HV) & $400 \mathrm{kV}$ \\
Rated voltage (LV) & $33 \mathrm{kV}$ \\
Rated current (HV) & $454.70 \mathrm{~A}$ \\
Rated current (LV) & $1837.00 \mathrm{~A}$ \\
Current Density & $0.28 \mathrm{~A} / \mathrm{mm}^{2}$ \\
No. of phase & 3 \\
Frequency & $50 \mathrm{~Hz}$ \\
Connection Symbol & $\mathrm{Yd} 11$ \\
Weight of core and coil & $129400 \mathrm{~kg}$ \\
Weight of tank and fittings & $32850 \mathrm{~kg}$ \\
Weight of Oil & $64090 \mathrm{~kg}$ \\
Rated top oil rise over ambient temperature & $45^{\circ} \mathrm{C}$ \\
Rated hot spot rise over top oil temperature & $55^{\circ} \mathrm{C}$ \\
Ratio of load loss at rated load to no-load loss & 2
\end{tabular}

$\begin{array}{ll}\text { Exponent ' } \mathrm{n} \text { ' } & 0.8 \\ \text { Exponent 'm' } & 0.9 \\ \text { No load loss } & 17500 \mathrm{~W} \\ \text { Relative winding eddy current losses } & 152 \mathrm{~W}\end{array}$

TABLE III: COOLING EQUIPMENT USED IN 315MVA 400kV/33kV POWER TRANSFORMER

\begin{tabular}{ccc}
\hline $\begin{array}{c}\text { Oil pumps \& Fans } \\
\text { capacity }\end{array}$ & Pump (600 gpm) & Fan (467 cum per min) \\
\hline $\begin{array}{c}\text { No. of oil pumps \& } \\
\text { fans }\end{array}$ & 4 & 10 \\
(Running + Standby) & $(2+2)$ & $(8+2)$ \\
\hline
\end{tabular}

TABLE IV: OTI AND WTI AUXILIARY CONTACTS SETTINGS

\begin{tabular}{cll}
\hline \hline & Alarm & $95^{\circ} \mathrm{C}$ \\
OTI & Trip & $100^{\circ} \mathrm{C}$ \\
\hline & Fan Start & $85^{\circ} \mathrm{C}$ \\
\multirow{2}{*}{ WTI } & Pump Start & $95^{\circ} \mathrm{C}$ \\
& Alarm & $115^{\circ} \mathrm{C}$ \\
& Trip & $125^{\circ} \mathrm{C}$ \\
\hline \hline
\end{tabular}

The thermal behavior of the power transformer has been evaluated and verified using the top oil and hot spot temperature models. Results of these thermal models for a power transformer are discussed in the following section. The typical load factor, total losses, ambient temperature, OTI and WTI reading for a $315 \mathrm{MVA}, 400 / 33 \mathrm{kV}$ power transformer located at 400kV GSS, Jodhpur are shown in Table V.

TABLE V: INPUT DATA TO A 315MVA TRANSFORMER

\begin{tabular}{cccccc}
\hline \hline $\begin{array}{c}\text { Clock } \\
\text { Time }\end{array}$ & $\begin{array}{c}\text { Foad } \\
\text { (K) })\end{array}$ & $\begin{array}{c}\text { Total } \\
\text { (Watts })\end{array}$ & $\begin{array}{c}\text { Ambient } \\
\text { Temperature } \\
\left({ }^{\circ} \mathrm{C}\right)\end{array}$ & $\begin{array}{c}\text { OTI } \\
\text { Reading } \\
\left({ }^{\circ} \mathrm{C}\right)\end{array}$ & $\begin{array}{c}\text { WTI } \\
\text { Reading } \\
\left({ }^{\circ} \mathrm{C}\right)\end{array}$ \\
\hline 6:00am & 0.57 & 685263 & 12 & 22 & 23 \\
7:00am & 0.59 & 685905 & 13 & 25 & 24 \\
8:00am & 0.61 & 696532 & 14 & 26 & 25 \\
9:00am & 0.71 & 745623 & 14 & 24 & 26 \\
10:00am & 0.78 & 795623 & 15 & 25 & 26 \\
11:00am & 0.79 & 797010 & 15 & 29 & 29 \\
12:00pm & 0.87 & 800100 & 17 & 28 & 29 \\
01:00pm & 0.89 & 812356 & 18 & 27 & 30 \\
02:00pm & 0.96 & 889654 & 18 & 26 & 31 \\
03:00pm & 1.08 & 895698 & 18 & 25 & 32 \\
04:00pm & 1.01 & 891258 & 18 & 30 & 32 \\
05:00pm & 0.99 & 889932 & 17 & 31 & 31 \\
06:00pm & 0.98 & 890008 & 15 & 32 & 30 \\
07:00pm & 1.04 & 895498 & 14 & 35 & 30 \\
08:00pm & 0.87 & 801124 & 14 & 36 & 28 \\
09:00pm & 0.85 & 790050 & 14 & 25 & 27 \\
10:00pm & 0.65 & 724613 & 13 & 26 & 24 \\
11:00pm & 0.64 & 734212 & 13 & 29 & 23 \\
12:00am & 0.55 & 686541 & 13 & 30 & 23 \\
01:00am & 0.56 & 686689 & 12 & 32 & 22 \\
02:00am & 0.57 & 689365 & 12 & 31 & 24 \\
03:00am & 0.59 & 690635 & 11 & 35 & 25 \\
04:00am & 0.61 & 696432 & 11 & 36 & 26 \\
05:00am & 0.54 & 685252 & 12 & 35 & 24 \\
\hline \hline & & & & & \\
\hline
\end{tabular}


The normal load profile of the $315 \mathrm{MVA}, 400 / 33 \mathrm{kV}$ power transformer for 24 hours in winter season (January) is shown in Fig. 2. It is clear from the Fig. 2, that the maximum value of the load factor is 1.08 occurring at $03: 00 \mathrm{pm}$.

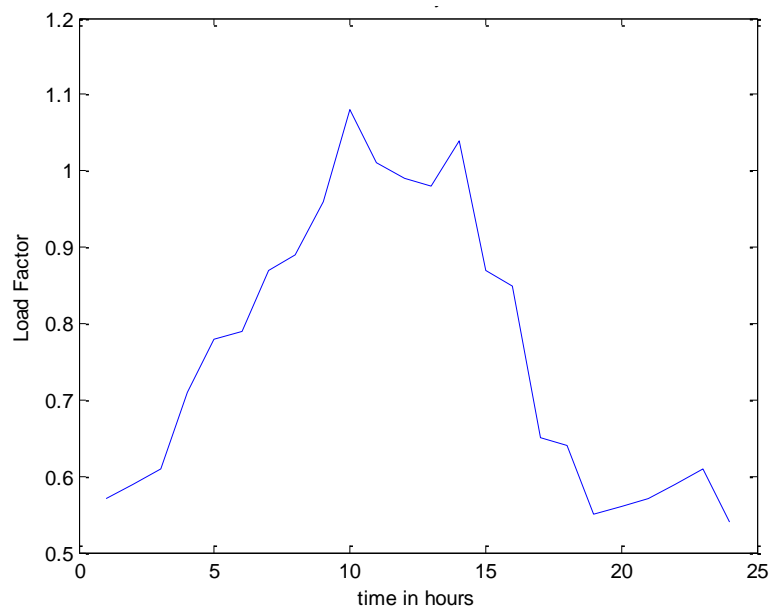

Fig. 2: Normal load cycle profile

The HST for every hour is evaluated by using a MATLAB program. The effect of heat dissipated due to various losses, i.e., constant and variable losses in a transformer on the useful life of a cellulose insulation material has first been estimated on a per unit basis. Cumulative loss of life has been calculated for varying load conditions with the understanding that one real day of operation will produce less or more aging than one day. Fig. 3 shows the graphical representation of the hot spot temperature for a day including the variation of the ambient temperature, the top oil temperature rise over ambient, and the hot spot temperature rise over top oil and the results are shown in Table VI. The graphical representation of transformer insulation life throughout a day is shown in Fig. 4.

TABLE VI: ANALYTICAL RESULTS FOR A 315MVA TRANSFORMER

\begin{tabular}{ccccccc}
\hline \hline $\begin{array}{c}\text { Clock } \\
\text { Time }\end{array}$ & $\Delta \theta_{\mathrm{TO}}$ & $\Delta \theta_{\mathrm{HS}}$ & $\theta_{\mathrm{H}}$ & $\mathrm{F}_{\mathrm{AA}}$ & $\begin{array}{c}\text { Aging } \\
\text { Hours }\end{array}$ & $\begin{array}{c}\text { Cumulat } \\
\text {-ive } \\
\text { Age } \\
\text { Hours }\end{array}$ \\
\hline 6:00am & 10.889 & 19.824 & 42.713 & 0.434 & 0.434 & 0.434 \\
7:00am & 26.374 & 21.299 & 60.673 & 0.560 & 0.560 & 0.994 \\
8:00am & 27.249 & 22.612 & 63.862 & 0.584 & 0.584 & 1.579 \\
9:00am & 27.598 & 29.659 & 71.257 & 0.643 & 0.643 & 2.222 \\
10:00am & 29.514 & 35.088 & 79.602 & 0.713 & 0.713 & 2.936 \\
11:00am & 31.944 & 35.922 & 82.866 & 0.741 & 0.741 & 3.678 \\
12:00pm & 32.856 & 42.686 & 92.543 & 0.829 & 0.829 & 4.507 \\
01:00pm & 32.742 & 44.467 & 95.210 & 0.854 & 0.854 & 5.362 \\
02:00pm & 34.111 & 50.931 & 103.042 & 0.930 & 0.930 & 6.292 \\
03:00pm & 36.410 & 62.904 & 117.314 & 1.076 & 1.076 & 7.368 \\
04:00pm & 37.349 & 55.788 & 111.137 & 1.011 & 1.011 & 8.380 \\
05:00pm & 37.412 & 53.816 & 108.228 & 0.982 & 0.982 & 9.362 \\
06:00pm & 37.713 & 52.838 & 105.551 & 0.955 & 0.955 & 10.317 \\
07:00pm & 40.691 & 58.774 & 113.465 & 1.035 & 1.035 & 11.352 \\
08:00pm & 37.346 & 42.678 & 94.024 & 0.843 & 0.843 & 12.196 \\
09:00pm & 30.743 & 40.929 & 85.673 & 0.766 & 0.766 & 12.962
\end{tabular}

\begin{tabular}{lllllll} 
10:00pm & 27.834 & 25.316 & 66.151 & 0.602 & 0.602 & 13.565 \\
11:00pm & 29.477 & 24.617 & 67.094 & 0.610 & 0.610 & 14.175 \\
12:00am & 28.937 & 18.787 & 60.724 & 0.560 & 0.560 & 14.736 \\
01:00am & 30.273 & 19.391 & 61.664 & 0.568 & 0.568 & 15.304 \\
02:00am & 29.780 & 20.030 & 61.810 & 0.569 & 0.569 & 15.873 \\
03:00am & 32.453 & 21.308 & 64.761 & 0.591 & 0.591 & 16.465 \\
04:00am & 33.296 & 22.621 & 66.917 & 0.608 & 0.608 & 17.074 \\
05:00am & 31.871 & 18.191 & 62.062 & 0.571 & 0.571 & 17.645 \\
\hline \hline
\end{tabular}

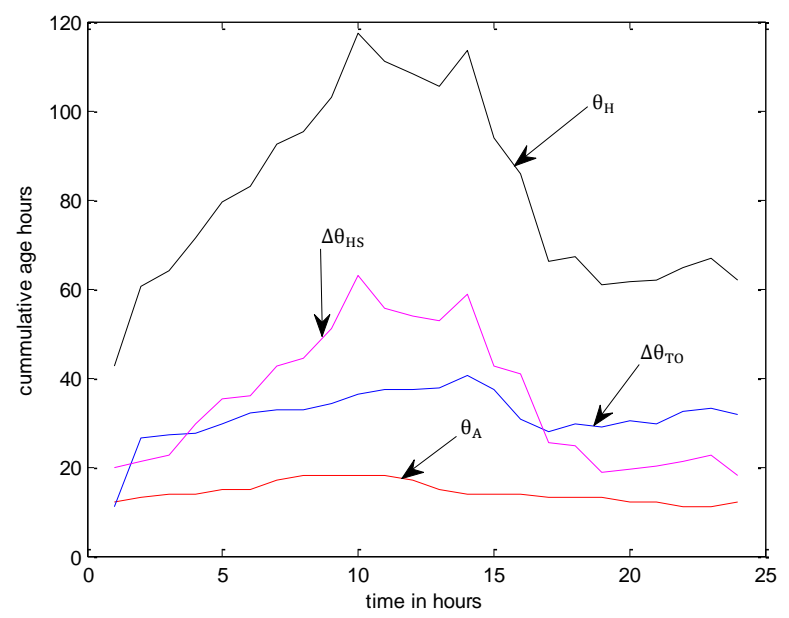

Fig. 3: Graphical representation of hot spot temperature, hot spot temperature rise, top oil temperature rise and ambient temperature

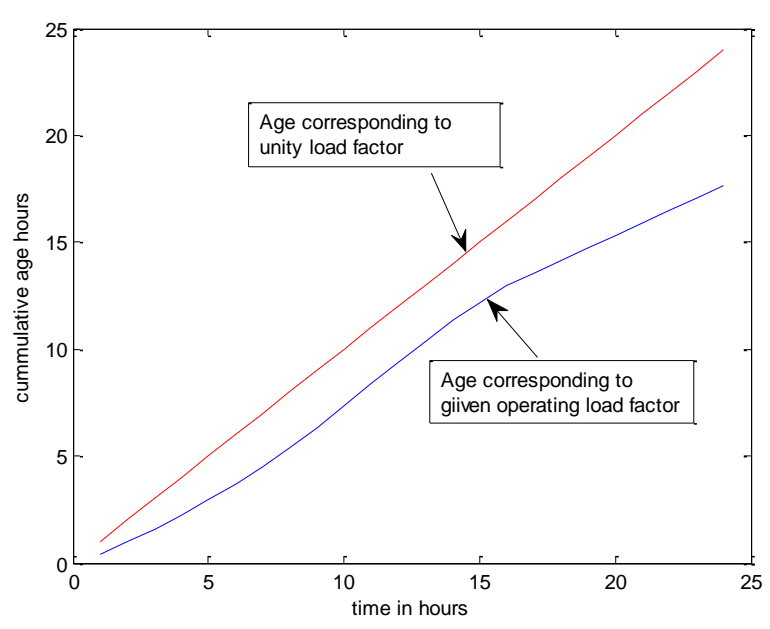

Fig. 4: Transformer insulation life

Now, a peak load having load factor of 1.5 is applied to the same transformer for an hour during a day results in a rise of hot spot temperature. Again, the cumulative loss of life is predicted, which will produce aging greater than 24 hours. Table VII shows the result of loss of life due to the impact of peak load on the transformer. The graphical representation of transformer insulation life when a peak load having load factor of 1.5 is applied for an hour during the same day is shown in Fig. 5. 
TABLE VII: PEAK LOAD APPLIED TO 315MVA TRANSFORMER

\begin{tabular}{cccccc}
\hline $\begin{array}{c}\text { Clock } \\
\text { Time }\end{array}$ & $\begin{array}{c}\text { Foad } \\
\text { Factor }\end{array}$ & $\theta_{\mathrm{H}}$ & Faa & $\begin{array}{c}\text { Aging } \\
\text { Hours }\end{array}$ & $\begin{array}{c}\text { Cumulative } \\
\text { Age Hours }\end{array}$ \\
\hline 6:00am & 0.57 & 42.713 & 0.434 & 0.434 & 0.434 \\
7:00am & 0.59 & 60.673 & 0.560 & 0.560 & 0.994 \\
8:00am & 0.61 & 63.862 & 0.584 & 0.584 & 1.579 \\
9:00am & 0.71 & 71.257 & 0.643 & 0.643 & 2.222 \\
10:00am & 0.78 & 79.602 & 0.713 & 0.713 & 2.936 \\
11:00am & 0.79 & 82.866 & 0.741 & 0.741 & 3.678 \\
12:00pm & 0.87 & 92.543 & 0.829 & 0.829 & 4.507 \\
01:00pm & 0.89 & 95.210 & 0.854 & 0.854 & 5.362 \\
02:00pm & 0.96 & 103.042 & 0.930 & 0.930 & 6.292 \\
03:00pm & $\mathbf{1 . 5 0}$ & $\mathbf{1 4 2 . 3 2 5}$ & $\mathbf{1 . 0 7 6}$ & $\mathbf{2 0 . 4 8 9}$ & $\mathbf{2 6 . 7 8 1}$ \\
04:00pm & 1.01 & 111.137 & 1.011 & 1.011 & 27.793 \\
05:00pm & 0.99 & 108.228 & 0.98 & 0.982 & 28.775 \\
06:00pm & 0.98 & 105.551 & 0.95 & 0.955 & 29.730 \\
07:00pm & 1.04 & 113.465 & 1.035 & 1.035 & 30.765 \\
08:00pm & 0.87 & 94.024 & 0.843 & 0.843 & 31.609 \\
09:00pm & 0.85 & 85.673 & 0.766 & 0.766 & 32.375 \\
10:00pm & 0.65 & 66.151 & 0.602 & 0.602 & 32.978 \\
11:00pm & 0.64 & 67.094 & 0.610 & 0.610 & 33.588 \\
12:00am & 0.55 & 60.724 & 0.560 & 0.560 & 34.149 \\
01:00am & 0.56 & 61.664 & 0.568 & 0.568 & 34.717 \\
02:00am & 0.57 & 61.810 & 0.569 & 0.569 & 35.286 \\
03:00am & 0.59 & 64.761 & 0.591 & 0.591 & 35.878 \\
04:00am & 0.61 & 66.917 & 0.608 & 0.608 & 36.487 \\
05:00am & 0.54 & 62.062 & 0.571 & 0.571 & 37.058 \\
\hline \hline & & & & & \\
\hline
\end{tabular}

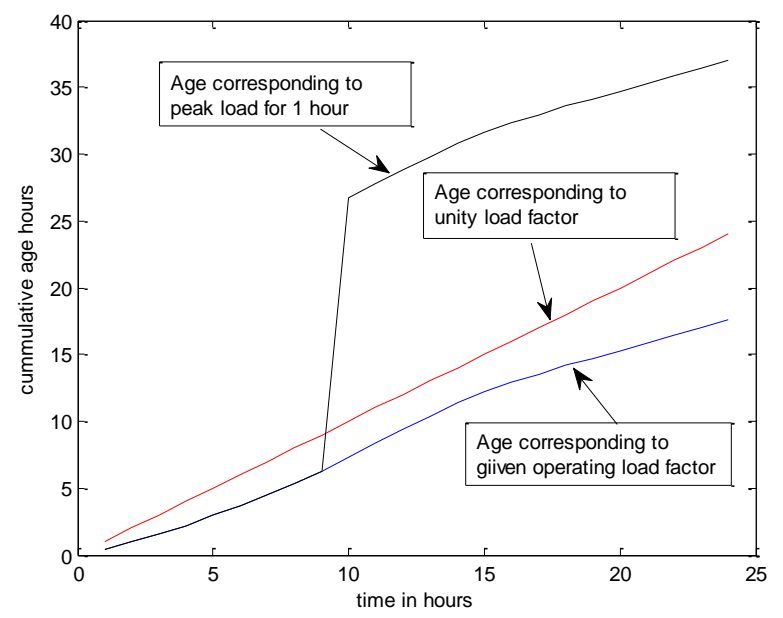

Fig. 5: Transformer insulation life corresponding to peak load for 1 hour

The normal insulation life at the reference temperature in hours is assumed to be 180000 . The percentage loss of life is evaluated for different load conditions as shown in Table VII.

It has been observed that employing ONAF cooling arrangement during peak load period reduces the hot spot temperature to $135^{\circ} \mathrm{C}$. The cumulative loss of life is now calculated again. This results in the saving in percentage loss of life as shown in Table VIII. The results obtained from thermal model may be used to estimate the residual life of the power transformer.

TABLE VIII: COOLING EQUIPMENT USED IN 315MVA 400kV/33kV POWER TRANSFORMER

\begin{tabular}{clc}
\hline \hline S. No. & \multicolumn{1}{c}{ Condition of Operation } & $\%$ loss of life \\
\hline 1 & Operating Load Factor every hour & 0.0098 \\
2 & Peak load factor for an hour & 0.0206 \\
3 & ONAF cooling during peak hour period & 0.0153 \\
\hline \hline
\end{tabular}

The proposed model gives the approximate HST values that are in close agreement with the measured field data. It can be concluded that with the increase in the transformer temperature beyond thermal limits would reduce its life below the specified normal life.

Further, the study of insulation ageing is important, as it reduces both the mechanical and dielectric-withstand strength of the transformer. An ageing transformer is subjected to faults that result in high radial and compressive forces. Also, the conductor insulation gets deteriorated and becomes unable to sustain the mechanical stresses caused by a fault. Hence, it is the dominant factor in limiting the lifetime of the transformer. Providing proper cooling such as ONAF has great potential to save the percentage loss of life.

The thermal model proposed in this paper is dependent on the accuracy of estimated steady-state temperature rises. Therefore, it will be important to develop a variable time interval calculation method with estimation at smaller time intervals when there are dynamic changes in temperature and larger intervals when the steady state is achieved. However, further research and development is needed to improve the existing monitoring systems and introduce designs and applications that include better thermal modeling. These thermal models will allow the transformer manufacturers to provide better specifications and users to operate the transformers on appropriate loading by considering the ambient temperature conditions.

\section{REFERENCES}

[1] Guide for Loading Mineral-Oil- Immersed Transformers, IEEE Standard C57.91-1995.

[2] Murtaza Hashmi, Matti Lehtonen, Seppo Hanninen, "Effect of Climate Change on Transformers Loading Conditions in the Future Smart Grid Environment", Open Journal of Applied Sciences, vol. 3, pp. 24 - 29, June, 2013. DOI:10.4236/ojapps.2013.32B005.

Available: http://www.scirp.org/journal/ojapps.

[3] Oluwaseun A. Amoda, Daniel J. Tylavsky, Gary A. McCulla and Wesley A. Knuth, "A New Model for Predicting Hottest-Spot Temperature in Transformers", IEEE Trans. Power Symposium, NAPS '08. 40th North American, pp. 1-8, 2008. DOI:10.1109/NAPS.2008.5307407.

[4] Shiyou WANG ,Youyuan WANG and Xuetong ZHAO, "Calculating Model of Insulation Life Loss of Dry-Type Transformer Based on the Hot-Spot Temperature", IEEE 11th International Conference on the Properties and Applications of Dielectric Materials, pp. 720-723, July 2015. DOI: 10.1109/ICPADM.2015.7295373.

[5] Juliano R. da Silva and Joao P. A. Bastos, "Analysis of Power Transformer Geometry Simplifications on Electromagnetic and Thermodynamic Simulations", IEEE Trans. on magnetics, vol. 51, no. 3, article 8400404, March, 2015. DOI: 10.1109/TMAG.2014.2358993.

[6] Muhammad Humayun, Mubbashir Ali, Amir Safdarian, Merkebu Z. Degefa, and Matti Lehtonen, "Optimal Use of Demand Response for Lifesaving and Efficient Capacity Utilization of Power Transformers 
during Contingencies", IEEE Trans. Power \& Energy Society General Meeting, pp. 1 - 5, 2015. DOI: 10.1109/PESGM.2015.7285627.

[7] Dong-Jin Kweon, Kyo-Sun Koo, Jung-Wook Woo and Joo-Sik Kwak, “A Study on the Hot Spot Temperature in $154 \mathrm{kV}$ Power Transformers", Journal of Electrical Engineering \& Technology, vol. 7, no. 3, pp. 312-319, 2012. Available: http://dx.doi.org/10.5370/JEET.2012.7.3.312.

[8] O.E. Gouda, G.M. Amer, W.A.A. Salem, "Predicting transformer temperature rise and loss of life in the presence of harmonic load currents", Ain Shams Engineering Journal, vol. 3, pp. 113-121, 2012. Available: www.elsevier.com/locate/asej.

[9] Diego M. Robalino Vanegas and Satish M. Mahajan, "Correlation between Hot-Spot Temperature and Aging Factor of Oil-Immersed Current Transformers", IEEE Trans. Power and Energy Society General Meeting - Conversion and Delivery of Electrical Energy in the $21 \mathrm{st}$ Century, pp. 1-5, 2008. DOI: 10.1109/PES.2008.4595981.

[10] Dejan Susa, Matti Lehtonen, and Hasse Nordman, "Dynamic Thermal Modelling of Power Transformers", IEEE Trans. on power delivery, vol. 20, no. 1, pp. 197-204, January 2005.

[11] Yong Liang, "Simulation of Top-Oil Temperature for Transformers", Thesis and Project Report, Power Systems Engineering Research Center Cornell University, New York, February 2001. Available: www.pserc.wisc.edu.

[12] N. A. Muhamad, H. Kamarden and N. A. Othman, "Heat Distribution Pattern of Oil-filled Transformer at Different Hottest Spot Temperature Locations", IEEE 11th International Conference on the Properties and Applications of Dielectric Materials, pp. 979-982, July 2015. DOI: 10.1109/ICPADM.2015.7295438.

[13] Longnv Li, Shuangxia Niu, S. L. Ho, W. N. Fu and Yan Li, “A Novel Approach to Investigate the Hot-Spot Temperature Rise in Power Transformers", IEEE Trans. on magnetics, vol. 51, no. 3, article 8400204, March, 2015. DOI: 10.1109/TMAG.2014.2359956.

[14] Zoran Radakovic, Uros Radoman, and Predrag Kostic, "Decomposition of the Hot-Spot Factor", IEEE Trans. on power delivery, vol. 30, no. 1, pp. 403 - 411, Feb, 2015. DOI: 10.1109/TPWRD.2014.2352039.

[15] M.Srinivasan and A. Krishnan, "Effects of Environmental Factors in Transformer's Insulation Life", WSEAS transactions on power systems, vol 8, Issue 1, Jan 2013.

[16] Kourosh Mousavi Takami, Hasan Gholnejad and Jafar Mahmoudi, "Thermal and hot spot evaluations on oil immersed power Transformers by FEMLAB and MATLAB software's", IEEE Trans. Thermal, Mechanical and Multi-Physics Simulation Experiments in Microelectronics and Micro-Systems, pp. 1-6, 2007. DOI: 10.1109/ESIME.2007.359924. 